\title{
Increased cancer mortality in Taiwanese inter-island migrants
}

\author{
Meng-Kan Chen ${ }^{1}$, Hsiu-Hsi Chen ${ }^{2}$ \\ ${ }^{1}$ Department of Family Medicine, National Taiwan University Hsin-Chu Branch, Taipei, Taiwan; ${ }^{2}$ Graduate \\ Institute of Epidemiology and Preventive Medicine, College of Public Health, National Taiwan University, \\ Taipei, Taiwan
}

\begin{abstract}
Higher mortality due to various forms of cancer was observed in emigrants, who had moved from the isolated and impoverished Taiwanese island of Matsu to the more affluent main island. A total of 13,691 ethnic Matsunese aged 30 years and above were enrolled in a study comparing cumulative and standardised mortality rates between emigrants to the main island of Taiwan and those who stayed behind. Poisson regression modelling was used to analyse the effects of migration. For all causes of mortality, the adjusted relative risk was 1.24 with a confidence interval (CI) at the 95\% level of 1.08-1.42 for emigrants compared to Matsunese non-emigrants. Deaths from cancer and diabetes in emigrants showed similar results, i.e. an adjusted relative risk of 1.25 (95\% CI, 1.00-1.57) and 1.93 (95\% CI, 1.20-3.11), respectively. Higher cumulative incidence rates for all cancers and the three leading cancer forms (hepatocellular carcinoma, gastric cancer and lung cancer) in emigrants were also observed. However, no significant difference in the survival time of most of the cancer forms was noted between the two groups. The finding that moving to a more affluent area paradoxically leads to incidence of cancer and higher mortality might be explained by adoption of various forms of unhealthy behaviour, psycho-social factors and the general risks related to life in urbanized environments.
\end{abstract}

Keywords: migration, mortality, cancer incidence, Taiwan.

\section{Introduction}

In Taiwan, the geographic difference in life expectancy between the northern and the eastern region is 6-7 years (Department of Health, 2006a,b). This is not exceptional as regional differences in life expectancy, morbidity and mortality have been reported worldwide. Examples include differences between regions in terms of premature mortality (Leyland, 2004), geographical variation in life expectancy due to deprivation in England (Woods et al., 2005), economic crisis and unevenly distributed societal factors in Russia (Men et al., 2003) and health inequality across countries in Western Europe (Mackenbach et al., 1997). In addition to genetic determinants, lifestyles and dietary habits as well as environmental factors (such as water, temperature and humidity) can be responsible for disparities in mortality and morbidity (Adler et al., 1994), which explains why migration-related health inequality is regarded as the key determinant with regard to geographical inequality (Brimblecombe et al., 2000;

\footnotetext{
Corresponding author:

Hsiu-Hsi Chen

Graduate Institute of Epidemiology and Preventive Medicine

College of Public Health, National Taiwan University

Room 533, No. 17, Hsuchow Road, Taipei 100, Taiwan

Tel. +88623366 8033; Fax +88622358 7707

E-mail: chenlin@ntu.edu.tw
}

Connolly et al., 2007). Migration-related health inequality also plays an important role for both domestic and international immigrants, but its influence is modified by gender, social class and migration characteristics (Malmusi et al., 2010).

The underlying theories accounting for migrationrelated health inequality are several. For example, the theory of selective migration holds that immigrants are more likely to be healthier than stationary people before migration (Brimblecombe et al., 2000; Connolly et al., 2007). However, despite socio-economic improvements, this effect may be transitory (Malmusi et al., 2010) as initial health advantages may gradually be lost due to "acculturation", i.e. difficulties in adapting to a new environment (Stephen et al., 1994; Uretsky and Mathiesen, 2007; Malmusi et al., 2010). Acculturation may lead to a sedentary life (Afable-Munsuz et al., 2010) or unhealthy dietary habits (Franzen and Smith, 2009) following migration. Such changes depend on the length of residence and the country of origin. They can even become a barrier for accessing available health care (Wells et al., 1987; Moore and Hepworth, 1994; O'Malley et al., 1999; Arcia et al., 2001), which may vary across the migrant group when compared to the native population of the host country, e.g. non-Spaniards have been shown to be less likely to visit a specialist after immigration to Spain (Hernández-Quevedo and Jiménez-Rubio, 2009). 
Most migration studies have focused on international migration (Newbold, 2005; Kelleher et al., 2006; Zunzunegui et al., 2006), while relatively few studies have investigated domestic migration, e.g. within Spain (Malmusi et al., 2010), within Indonesia (Lu, 2008) and within Beijing (Chen, 2011). Although international migration is associated with longer distances and produces a "healthy-migrant" effect (health screening at entrance) and thus produce a greater barrier for migration than domestic migration, selective, domestic migration may be more complex than international migration. The healthy-migrant effect is deemed the net aggregate from positive selection (work-related migrants, younger migrants and those with higher levels of education) and negative selection (elderly migrants and sick people). Young people have a higher likelihood of migration, whereas higher family income diminishes the possibility of migration (Lu, 2008). A domestic migration study in the People's Republic of China (P.R. China) found the healthy-migrant effect among migrants to be affected by self-rated physical health, but it was unrelated to psychological distress (Chen, 2011). The physical activity advantage diminished in proportion to the length of residency in the new place, but an initial mental disadvantage improved in urban-to-urban migrants (Chen, 2011). Most migration studies use comprehensive variables of socio-economic status but the dependent variable is often based on self-rated health status instead of an actual, standardised health indicator (Dunn and Dyck, 2000; Boyle et al., 2002; Hernández-Quevedo and JiménezRubio, 2009; Malmusi et al., 2010). Indeed, it is well known that acculturation and health status vary depending on the use of self-rated health status and an actual health indicator (Markides and Lee, 1991; Ontiveros et al., 1999).

Comparison of mortality and morbidity of local residents living in a deprived environment to those of emigrants moving to a more affluent area based on an internal migration (inter-island) was felt to be of interest from the socio-epidemiological viewpoint. It would also be useful to compare the health status of emigrants with that of another, stationary group of the same ethnicity by assessing incidence of disease, survival and mortality. In addition to common factors related to demographic features such as gender, social class and selective migration, the former group provides an insight into the aetiology and causes of disease that may be affected by the process of acculturation, whereas the latter reveals the influence of availability of and accessibility to medical care. On the basis of an inter-island migration study that largely dispenses with ethnic differences and also, though less completely, influences from acculturation and assimilation, we were able to assess how the health status evolved with respect to emigrants from the Matsu archipelago (an economically less developed area) to the main island of Taiwan (a highly developed area) on the one hand, and people who did not migrate on the other. Thus, we were dealing with people with similar ethnicity, cultural behaviour and lifestyles, some of whom moved from one part of the country (the Matsu islands) to another (Taiwan island). This situation provided us with a natural opportunity to investigate how morbidity and mortality changed as a result of the emigration from a deprived area to an affluent one with other variables staying the same. In order to explore the possible impact of selective migration and acculturation on the incidence of disease and survival (the healthy-migration effect), general mortality and the incidence of leading cancers and major chronic diseases were compared between stationary Matsunese and the Matsu emigrants to Taiwan Island, where better accessibility to medical care is supposed to contribute to higher survival.

Since the emigrants from the Matsu archipelago to Taiwan island have a similar ethnicity and both islands are separated by the Taiwan Strait with very limited transportation facilities, this represents a strict interisland migration situation offering us an opportunity to investigate how morbidity and mortality changed as a result of the move from a low income area to a prosperous area.

\section{Materials and methods}

\section{Study area and background data}

The offshore islands of Matsu belong to Lienchiang county and cover a total area of 25,052 ha. They are composed of five large and several smaller islands, which are administratively divided into the four villages of Nangan, Beigan, Jyuguang and Dongyin. According to the national census of 1997 5,360 people live on the Matsu islands with more than $60 \%$ of the population living in Nangan. The military fort of the Republic of China (R.O.C.), Taiwan is housed in Matsu since 1949. This has limited the economic development of this part of Taiwan, where the local residents live from fishing and have scarce medical resources. Stimulated by the economic development in R.O.C. that started in the early 1990s, many people left Matsu for the main island of Taiwan. Before that time, migration to Taiwan was rare and strictly regu- 
lated due to military reasons. According to the R.O.C. General Directorate of Budget, Accounting and Statistics (2005), the annual per capita gross domestic product of the Matsu islands was only $68 \%$ of that in the rest of the country in 1998 but it had grown to $83 \%$ in 2005 corresponding to US\$ 8,511 and US\$ 13,332, respectively. Compared to Taiwan Island, the proportion of illiterates of ages 15 years and above has been higher $(5.1-12.6 \%$ in Matsu versus $2.0-5.1 \%$ in Taiwan) since 1998. The proportion of unemployment was lower in Matsu (1.1-1.6\%) compared with that in Taiwan (2-5\%) between 2002 and 2005. Although the average number of people per physician (390-904 in Matsu versus 522-715 in Taiwan Island) and the average number of hospital beds per 100,000 people (3678 in Matsu versus 56-68 in Taiwan Island) were similar in the period 1998-2010, Matsu has still only one district-level hospital that ranks far below a medical centre with various specialities and teaching facilities. The people remaining on the Matsu islands have lower standardised, all-cause mortality per 100,000 compared with those who have lived on Taiwan Island (450.6 in 2005 and 317.6 in 2010 in Matsu versus 530.0 in 2005 and 455.6 in 2010 in Taiwan). For those living in the two counties Taoyuan and Taipei in the main island of Taiwan, where most of the Matsu emigrants took residence, the corresponding figures for all-cause mortality were 506.3 and 480.8 in 2005 , which had decreased to 440.0 and 413.3 in 2010 (Department of Health, 2006a, 2011).

\section{Study population}

By cross-checking the population registry for the Matsu islands of 1997, we identified 13,694 people (Fig. 1), who were either resident in Matsu since birth (3,666 people) or who had immigrated to Taiwan Island (10,025 people). It should be noted that out of 5,360 registered residents, 1,694 were excluded because they were not native Matsunese by ancestry. After excluding three people who had died before 1997, a total of 13,691 people formed the dataset used for analysis.

The study migrant cohort was mainly first-generation people since migration was seldom long enough to allow inclusion of many second-generation subjects aged 30 years or above in 1997 and claiming from the Bureau of National Health Insurance (NHI) was not possible until 1995. This nationwide insurance programme covers all living on Taiwan Island including the Matsu islands. The coverage rate is up to $98 \%$ as reported in a previous study (Wen et al., 2008).

\section{Study design}

We aimed to compare incidence and mortality rates of the major diseases, including leading cancers and chronic diseases, between emigrants from Matsu to Taiwan Island and stationary Matsunese people. Unlike other international migration studies, we did not compare health consequences between migrants

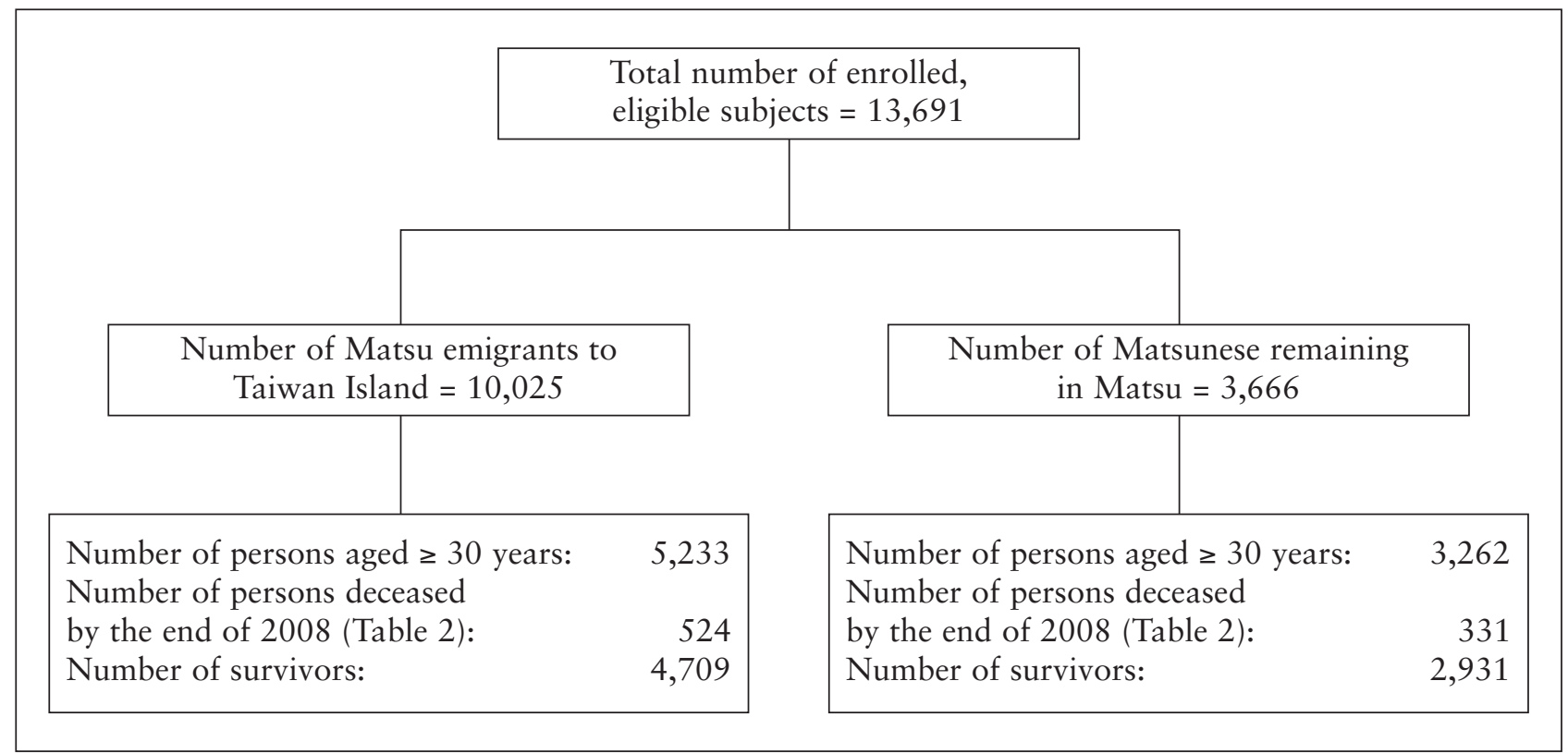

Fig. 1. Inter-island migration study. 
and people living in the receiving host city but between people of the same ethnicity and language in two areas characterised by different levels of socio-economic development. We accounted for both incidence and survival in an attempt to separate biological causes (that mainly influences incidence) from the quality and utilization of medical care (that is mainly related to survival).

Demographic characteristics were compared between the two groups, including sex and age distribution. Regarding the comparison of mortalities in stationary Matsunese and Matsu emigrants, only those aged 30 years and above were linked to the National Mortality Database (NMB) from 1997 to 2008 because death was expected to be rare in those less than 30 years old. The cause of death was classified according to the ICD-9 code recorded in the NMB.

Cancer incidence rates were calculated by linking the 1996-2001 cancer registry dataset to the Matsu population registry database and NHI claims in 1997, which was further validated to the year 1996 by linkage through the NMB. There were 268 cancer patients diagnosed between 1996 and 2001, including 98 Matsunese residents and 170 Matsu emigrants, respectively. Survival with respect to all cancers and that of the separate leading cancers was calculated by linking the 1996-2001 cancer registry dataset to the NMB. The incidence of chronic disease in Matsu was taken from a community-orientated screening programme, introduced by the Public Health Bureau of Lienchiang county in 2002 and running since then. This programme is not only tailored for the incidence rates of cancer but also for major chronic diseases such as cardiovascular disease, diabetes mellitus and stroke. The corresponding information from Taiwan Island was mainly based on claims from NHI.

\section{Statistical analysis}

The mean age between the two groups was compared using the $t$-test, and the sex proportion was compared using the $\chi^{2}$ test. The cumulative mortality in those aged $\geq 30$ years from 1997 to 2008 was estimated using Cox proportional-hazards regression model (Andersen, 1992; Chen et al., 2005) (see Appendix). The mortalities for all causes, cancer in general, specific cancers, cerebral vascular disease, heart disease and diabetes were compared between the two groups using the people on Taiwan Island in 1970 as the standard population. To evaluate whether specific disease mortalities differed between the two groups, a Poisson regression model was used to estimate the relative risk in the groups after adjustment for age and sex in death from all causes, cancer in general, specific cancers, cerebral vascular disease, heart disease and diabetes.

Cumulative incidence rates of cancer from 1996 to 2001 were estimated and plotted using Cox proportional-hazards regression model (see Appendix). Standardised cancer incidences of those aged $\geq 30$ years from 1996 to 2001 in the two groups were calculated using the population in 1970 as the standard and SAS version 9.1 (SAS Institute, Cary, NC, USA) for statistics.

\section{Results}

\section{Basic characteristics}

Table 1 shows the age distribution of the stationary Matsunese and the Matsu emigrants. The mean age of the emigrants was lower than that of those who stayed in Matsu by 12.9 years for males $(\mathrm{P}<0.001)$ and 15.9 years for females $(\mathrm{P}<0.001)$. Most emigrants were

Table 1. Age and gender distribution between stationary Matsunese and Matsu emigrants in 1997.

\begin{tabular}{|c|c|c|c|c|c|c|c|c|c|c|c|c|}
\hline \multirow{3}{*}{$\begin{array}{l}\begin{array}{l}\text { Age } \\
\text { (years) }\end{array} \\
0-19\end{array}$} & \multicolumn{6}{|c|}{ Stationary Matsunese } & \multicolumn{6}{|c|}{ Matsu emigrants } \\
\hline & \multicolumn{2}{|c|}{ Male } & \multicolumn{2}{|c|}{ Female } & \multicolumn{2}{|c|}{ Subtotal } & \multicolumn{2}{|c|}{ Male } & \multicolumn{2}{|c|}{ Female } & \multicolumn{2}{|c|}{ Subtotal } \\
\hline & 7 & $(0.2 \%)$ & 9 & $(0.3 \%)$ & 16 & $(0.4 \%)$ & 1,078 & $(10.8 \%)$ & 1,083 & $(10.8 \%)$ & 2,161 & $(21.6 \%)$ \\
\hline $20-29$ & 248 & $(6.8 \%)$ & 140 & $(3.8 \%)$ & 388 & $(10.6 \%)$ & 1,134 & $(11.3 \%)$ & 1,497 & $(14.9 \%)$ & 2,631 & $(26.2 \%)$ \\
\hline $30-39$ & 641 & $(17.5 \%)$ & 383 & $(10.5 \%)$ & 1,024 & $(27.9 \%)$ & 1,175 & $(11.7 \%)$ & 1,352 & $(13.5 \%)$ & 2,527 & $(25.2 \%)$ \\
\hline $40-49$ & 452 & $(12.2 \%)$ & 391 & $(10.7 \%)$ & 843 & $(23.0 \%)$ & 513 & $(5.1 \%)$ & 523 & $(5.2 \%)$ & 1,036 & $(10.3 \%)$ \\
\hline $50-59$ & 318 & $(8.7 \%)$ & 207 & $(5.7 \%)$ & 525 & $(14.3 \%)$ & 274 & $(2.7 \%)$ & 322 & $(3.2 \%)$ & 596 & $(6.0 \%)$ \\
\hline $60-69$ & 230 & $(6.3 \%)$ & 252 & $(6.9 \%)$ & 482 & $(13.2 \%)$ & 212 & $(2.1 \%)$ & 284 & $(2.8 \%)$ & 496 & $(5.0 \%)$ \\
\hline$\geq 70$ & 185 & $(5.1 \%)$ & 203 & $(5.5 \%)$ & 388 & $(10.6 \%)$ & 283 & $(2.8 \%)$ & 295 & $(2.9 \%)$ & 578 & $(5.8 \%)$ \\
\hline Total & 2,081 & $(56.8 \%)$ & 1,585 & $(43.2 \%)$ & 3,666 & $(100 \%)$ & 4,669 & $(46.6 \%)$ & 5,356 & $(53.4 \%)$ & 10,025 & $(100 \%)$ \\
\hline
\end{tabular}


Table 2. Mortality in stationary Matsunese and Matsu emigrants from January 1997 to December 2008 in people aged $\geq 30$ years.

\begin{tabular}{|c|c|c|c|c|}
\hline \multirow[b]{2}{*}{ All causes } & \multicolumn{2}{|c|}{ Stationary Matsunese $(\mathrm{n}=3,262)$} & \multicolumn{2}{|c|}{ Matsu emigrants $(\mathrm{n}=5,233)$} \\
\hline & 331 & & 524 & \\
\hline Cancer & 129 & $(39.0 \%)$ & 199 & $(38.0 \%)$ \\
\hline Hepatocellular carcinoma & 30 & & 53 & \\
\hline Gastric cancer & 24 & & 41 & \\
\hline Lung cancer & 23 & & 26 & \\
\hline Esophageal cancer & 8 & & 10 & \\
\hline Colon cancer & 8 & & 12 & \\
\hline Other cancers & 36 & & 57 & \\
\hline Diabetes & 24 & $(7.3 \%)$ & 58 & $(11.1 \%)$ \\
\hline Heart disease & 28 & $(8.5 \%)$ & 53 & $(10.1 \%)$ \\
\hline Cerebral vascular disease & 33 & $(10.0 \%)$ & 50 & $(9.5 \%)$ \\
\hline Accident & 24 & $(7.3 \%)$ & 31 & $(5.9 \%)$ \\
\hline Lung disease & 18 & $(5.4 \%)$ & 38 & $(7.3 \%)$ \\
\hline Liver cirrhosis & 10 & $(3.0 \%)$ & 15 & $(2.9 \%)$ \\
\hline Other & 65 & $(19.6 \%)$ & 80 & $(15.3 \%)$ \\
\hline
\end{tabular}

younger, while the stationary Matsunese were older, comprising a quarter of the residents aged 60 and above. In the $\geq 30$-years-old group, the differences in mean age were 2.43 years for males $(\mathrm{P}<0.001)$ and 5.5 years for females $(\mathrm{P}<0.001)$. The gender distribution was significantly different between the two groups: $56.8 \%$ of males among the stationary Matsunese, which was higher than that in the Matsu emigrant group $(46.6 \%)(\mathrm{P}<0.001)$.

\section{Mortality}

After a 12-year follow-up, 331 deaths of 3,262 stationary Matsunese and 524 deaths of 5,233 Matsu emigrants were ascertained in those aged 30 years or above. Cancer was the leading cause in both groups, accounting for almost $40 \%$ of all causes of deaths. Heart disease, cerebral vascular disease and diabetes were the three major causes of death, accounting for $7-11 \%$ of the mortality (Table 2 ). In both groups, the leading cause of cancer was hepatocellular carcinoma, followed by cancers of the stomach and lung.

The cumulative mortality between 1997 and 2009 for all causes of death, as well as for the major ailments charted separately, were higher in the Matsu $\geq 30$-years-old emigrant group than it was for those who stayed in Matsu (Fig. 2). Interestingly, however, the cumulative mortality due to lung cancer was very similar. Table 3 presents a comparison between the two groups with respect to the standardised mortality rates of cause-specific death from 1997 to 2008. The all-cause mortality rate for the Matsu emigrants was approximately 1.37-fold compared to that of the stationary Matsunese. Taken separately, the standardised mortality rates for the major causes of death (including cancer, heart disease, cerebral vascular disease, diabetes, lung disease and liver cirrhosis) in the Matsu emigrants were higher than in the stationary Matsunese group with relative rates ranging from 1.34 to 2.01 . Notably, with exception of cancer of the oesophagus, the standardised mortality rates for the specific cancers were higher for the Matsu emigrants compared to the stationary Matsunese. It was also noted that deaths from injury and unclassified causes such as senility, cardiac arrest, etc. were similar in both groups.

When the mortality rates from 1997 to 2008 were analysed by Poisson regression based on the total study population (stationary and emigrants together) in 1997 adjusted for age and sex, the emigrants had a $24 \%$ higher all-causes mortality risk than the stationary Matsunese with the relative risk $(\mathrm{RR})=$ 1.24, 95\% CI, 1.08-1.42 (Table 3). Mortality due to cancer $(\mathrm{RR}=1.25,95 \% \mathrm{CI}, 1.00-1.57)$ and diabetes mellitus $(\mathrm{RR}=1.93,95 \% \mathrm{CI}, 1.20-3.11)$ was similar. Although the risk for death from heart disease $(\mathrm{RR}=1.46,95 \% \mathrm{CI}, 0.92-2.31)$, hepatocellular carcinoma $(\mathrm{RR}=1.45,95 \% \mathrm{CI}, 0.93-2.29)$ and stomach cancer $(\mathrm{RR}=1.41,95 \% \mathrm{CI}, 0.85-2.34)$ was also higher in the emigrants than in the stationary Matsunese, it was not significant. The difference 
A)

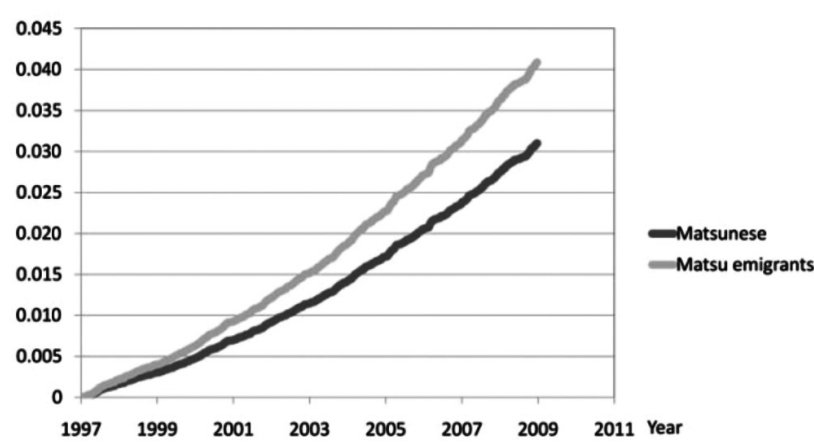

C)

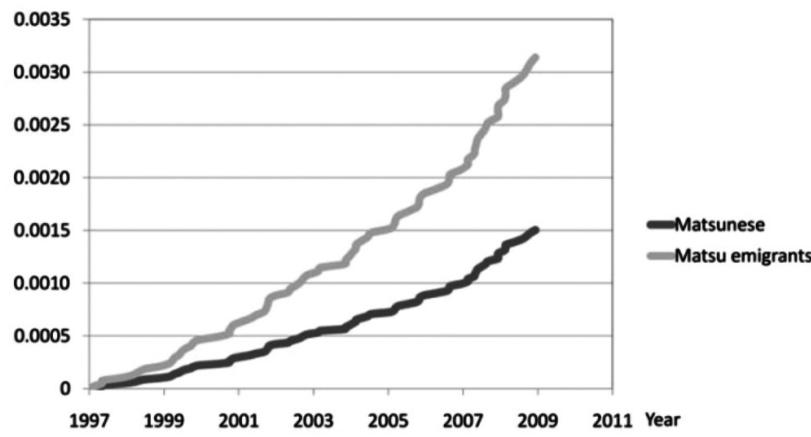

E)

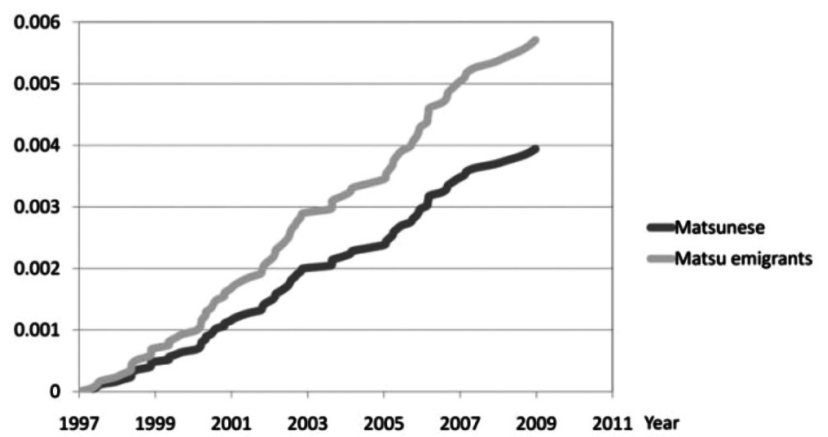

B)

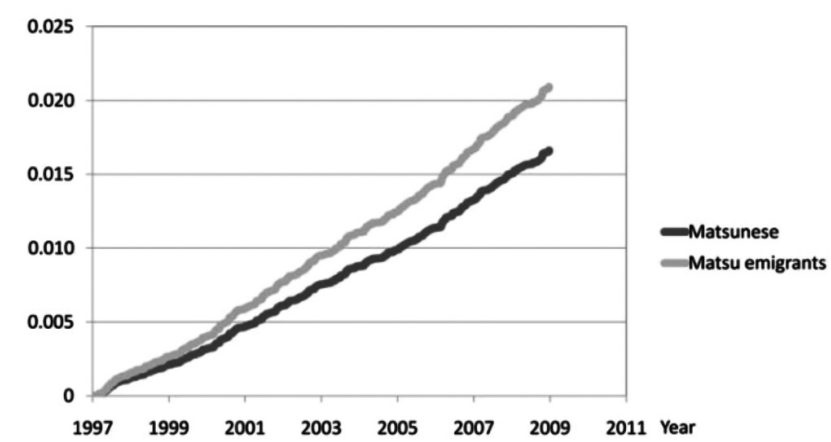

D)

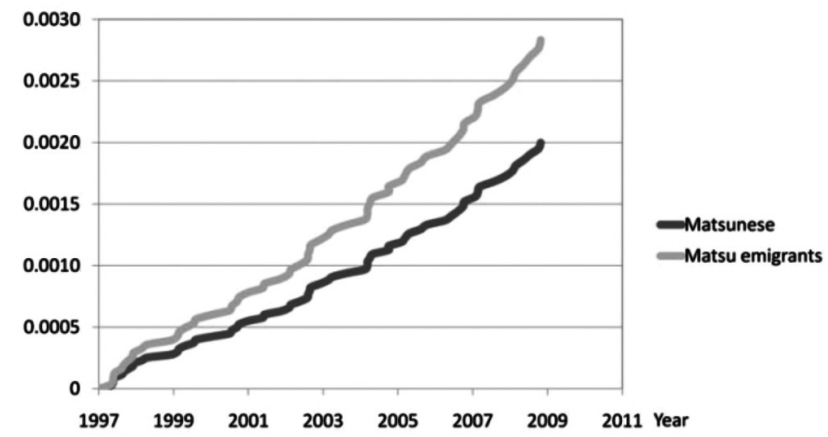

F)

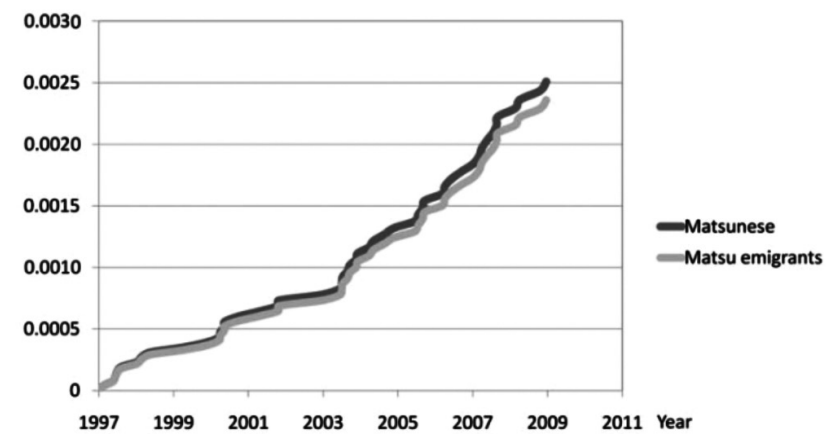

Fig. 2. Cumulative all-cause (A) and leading-cause mortality rates (B, all cancer; C, diabetes mellitus; D, gastric cancer; E, hepatocellular cancer; F, lung cancer) in $\geq 30$-year-old stationary Matsunese and Matsu emigrants with a 12-year follow-up.

attributable to death from lung cancer was similar in both groups. Other mortalities were too sparse to calculate the adjusted, RR estimates.

\section{Cancer incidence}

Cumulative incidence rates of all cancers as well as the three leading cancers counted separately were higher in the Matsu emigrants than in the Matsunese (Fig. 3). A comparison of age- and sex-standardised incidences of cancer between the two groups between 1996 and 2001 shows that the incidence rate of all cancers in the Matsu emigrants was slightly higher than that in the stationary Matsunese $\left(552.5 \times 10^{-5} /\right.$ person year and $424.1 \times 10^{-5} /$ person year, respectively (Table 4). The Matsu emigrants had approximately 1.5 -fold the incidence rate of gastric cancer and hepatocellular carcinoma, and 3-fold the incidence rate of lung cancer compared to the stationary Matsunese.

When the mortality rates from 1996 to 2001 were analysed by Poisson regression based on the total study population (stationary and emigrants together) in 1996 adjusted for age and sex, the emigrants had a $42 \%$ higher risk for cancer occurrence compared to the stationary Matsunese $(\mathrm{RR}=1.42,95 \% \mathrm{CI}, 1.10$ - 
Table 3. Standardised mortality rates in stationary Matsunese and Matsu emigrants in those aged $\geq 30$ years with a 12-year followup plus age- and sex-adjusted relative risk of all-cause mortality and cause-specific mortality.

\begin{tabular}{lccccc}
\hline Mortality 1997-2008* & $\begin{array}{c}\text { Stationary Matsunese } \\
\text { per } 10^{5} \text { person years }\end{array}$ & $\begin{array}{c}\text { Matsu emigrants } \\
\text { per } 10^{5} \text { person years }\end{array}$ & Adjusted RR (95\% CI) & P-value \\
\hline All causes & 474.9 & 651.8 & 1.24 & $(1.08,1.42)$ & 0.002 \\
Cancer & 207.3 & 278.4 & 1.25 & $(1.00,1.57)$ & 0.049 \\
Hepatocellular carcinoma & 56.9 & 84.7 & 1.45 & $(0.93,2.29)$ & 0.105 \\
Gastric cancer & 29.6 & 57.4 & 1.41 & $(0.85,2.34)$ & 0.185 \\
Lung cancer & 28.5 & 36.0 & 0.95 & $(0.54,1.67)$ & 0.861 \\
Esophageal cancer & 11.5 & 9.5 & & - & - \\
Colon cancer & 12.30 & 16.2 & & - & - \\
Other cancers & 68.6 & 74.6 & & - & 0.007 \\
Diabetes & 31.8 & 64.0 & 1.93 & $(1.20,3.11)$ & 0.106 \\
Heart Disease & 32.6 & 53.9 & 1.46 & $(0.92,2.31)$ & 0.470 \\
Cerebral vascular disease & 36.7 & 57.2 & 1.18 & $(0.76,1.83)$ & 0.687 \\
Accident & 48.0 & 44.7 & 0.89 & $(0.52,1.54)$ & - \\
Lung disease & 22.4 & 36.9 & & - & - \\
Liver cirrhosis & 17.7 & 26.7 & & & - \\
Other & 78.4 & 90.0 & & & - \\
\hline
\end{tabular}

*Standardised by the 1970 population in Taiwan.

A)

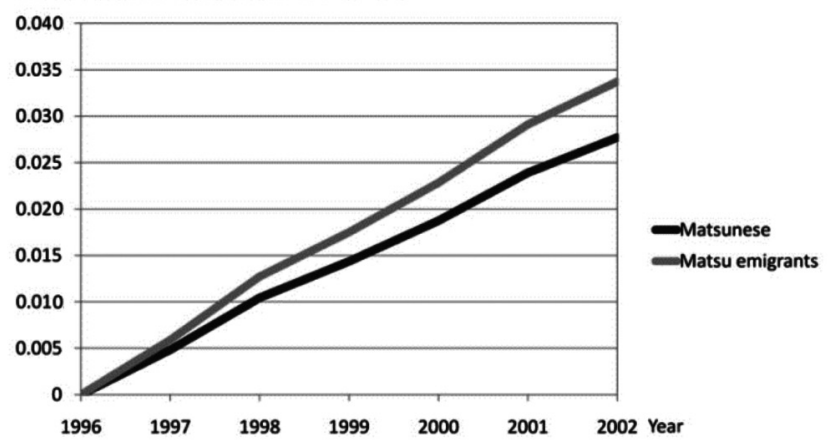

C)

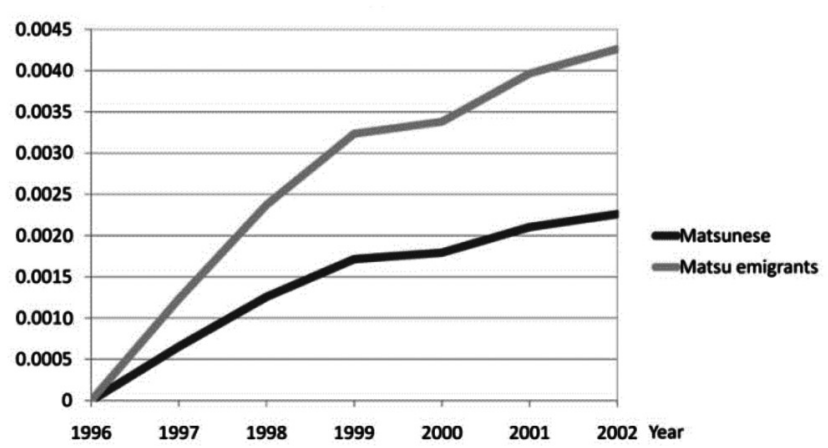

B)

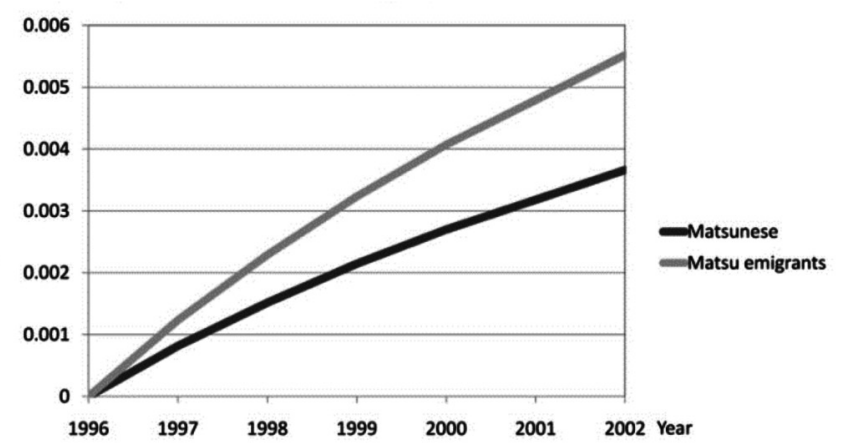

D)

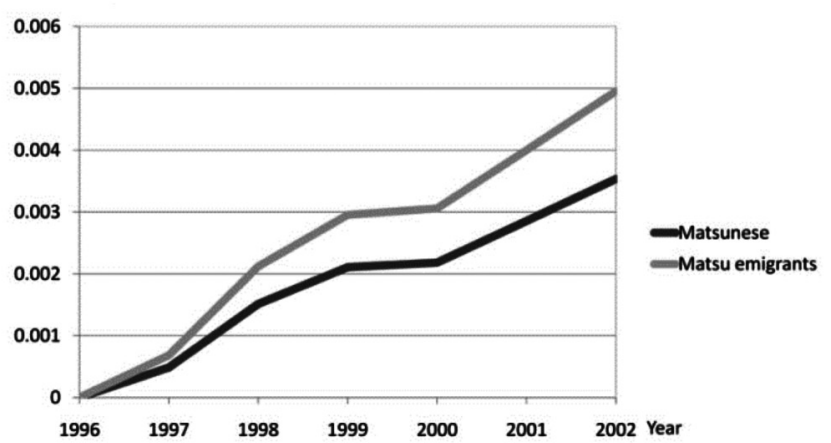

Fig. 3. Cumulative incidence of all cancers (A) and leading cancers (B, gastric cancer; C, lung cancer; D hepato-cellular carcinoma) in $\geq 30$-year-old in stationary Matsunese and Matsu emigrants from 1996 to 2001. 
Table 4. Standardised incidence of cancer in stationary Matsunese and Matsu emigrants with a 6-years follow-up plus age- and sexadjusted relative risk of incidence of cancer.

\begin{tabular}{lccccc}
\hline Incidence 1996-2001* & $\begin{array}{c}\text { Stationary Matsunese } \\
\text { per 105 }\end{array}$ & $\begin{array}{c}\text { Matsu emigrants } \\
\text { per } 10^{5} \text { person yrs }\end{array}$ & Adjusted RR (95\% CI) & P-value \\
\hline All cancer & 424.1 & 552.5 & 1.42 & $(1.10,1.83)$ & 0.007 \\
Hepatocellular carcinoma & 95.4 & 144.6 & 1.64 & $(0.94,2.87)$ & 0.081 \\
Gastric cancer & 68.3 & 98.6 & 1.72 & $(0.93,3.20)$ & 0.084 \\
Lung cancer & 26.9 & 75.7 & 2.24 & $(0.99,5.05)$ & 0.052 \\
\hline
\end{tabular}

*Standardised by the 1970 population in Taiwan.

1.83). With respect to the risk for hepatocellular carcinoma $(\mathrm{RR}=1.64,95 \% \mathrm{CI}, 0.94-2.87)$ and stomach cancer $(\mathrm{RR}=1.72,95 \% \mathrm{CI}, 0.93-3.20)$, the emigrants were higher than the stationary Matsunese but the outcome was not statistically significantly. The incidence of lung cancer was higher in Matsu emigrants than in the stationary Matsunese $(\mathrm{RR}=2.24,95 \%$ CI, 0.99-5.05) but the significance was only borderline.

\section{Cancer survival}

Differences in survival rates of all cancers were statistically non-significant between the two study groups regardless of adjustment for sex and age (Table 5 and Fig. 4). The analysis showed no statistically significant difference in the survival of stomach cancer and lung cancer, regardless of whether or not it was adjusted for sex and age (Table 5). Surprisingly, for male patients with hepatocellular carcinoma, the survival time for the stationary Matsunese was longer than that for the Matsu emigrants $(\mathrm{P}<0.01)$. Overall, the survival time of cancer in the former group was similar to that in latter with the exception of male patients with hepatocellular carcinoma.

Table 5. Adjusted Hazard Ratio a of Survival of cancer patients (diagnosed in 1996-2001) for the stationary Matsunese versus the Matsu emigrants (follow-up period: 1996-2005).

\begin{tabular}{lccc}
\hline & Adjusted HR & $95 \%$ CI & P-value \\
\hline Cancer & 0.76 & $(0.54,1.05)$ & 0.099 \\
Specific cancer & & & \\
Gastric cancer & 1.13 & $(0.52,2.47)$ & 0.760 \\
Hepatocellular carcinoma & 0.32 & $(0.14,0.72)$ & 0.006 \\
Lung cancer & 1.28 & $(0.49,3.33)$ & 0.620 \\
\hline
\end{tabular}

Extraneous factors adjusted in the model include age and sex.

\section{Discussion}

The unique characteristic of this inter-island migration study was to compare mortality, incidence and survival between two groups that only differed with respect to relative economic affluence. The results indicate that the differences in mortality (Fig. 2) are largely attributable to the difference in incidence rates rather than survival. The occurrence of cancer is often a multi-factorial process, including both genetic and non-genetic factors (Guilbert, 2003). As this was a domestic study, non-genetic factors should be the major determinants and the outcome could be related to the environment (be it urbanized, outdoor, indoor or work-related), negative acculturation such as the adoption of unhealthy behaviour prevalent in the receiving society (e.g. smoking, drinking, etc.) or psycho-social factors appearing after migration.

We have demonstrated that mortality of all causes and that for the major diseases is lower in those remaining in Matsu compared to those who migrated to more affluent areas, i.e. Taiwan Island. Our results, contrary to the expected lower mortality in the group that migrated from a deprived area to an affluent one, are consistent with the influence of acculturation previously shown to be responsible for migration-related health inequalities, e.g. change of physical activity (Abraido-Lanza et al., 1999) and dietary habits (Franzen and Smith, 2009). Even if a healthy immigrant effect should be beneficial initially, the effect may be transitory as proposed by Malmusi et al. (2010). However, the better accessibility to medical care after migration, or the chance that the emigrants may have achieved a better socio-economic status, could explain the fact that the cancer survival was identical between the two groups.

Instead of adopting better living standards, the Matsu emigrants might have lost their initial healthrelated advantage by the long duration of a paradoxically less healthy life on the main island, a situation 

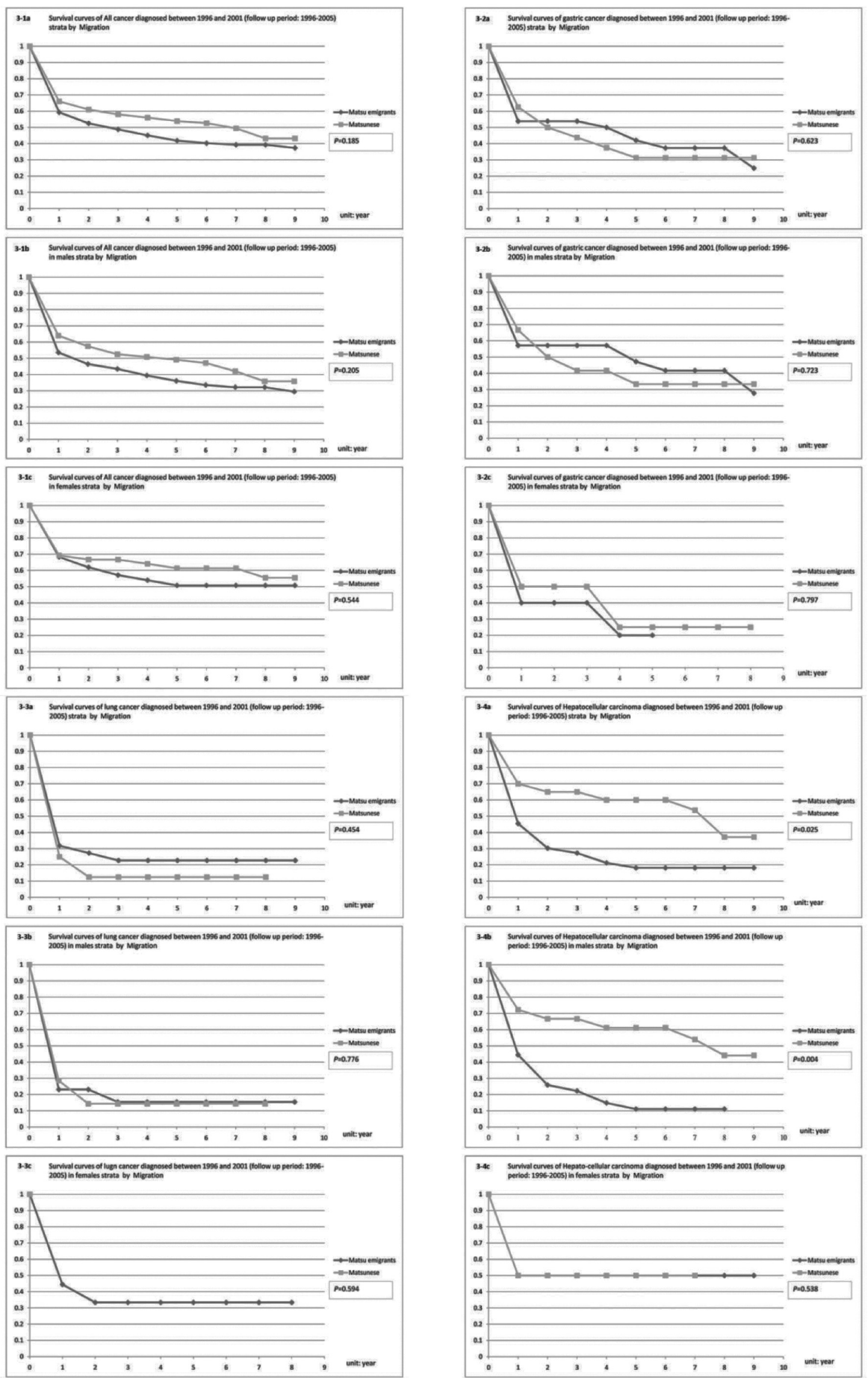

Fig. 4. Survival curves of all cancers and leading cancers diagnosed between 1996 and 2001 followed up from 1996 to 2005. 
not unlike that described in a rural-to-urban migration study in P.R. China (Chen, 2011). In addition, immigrants often sacrifice quality of life for a better education for their children, thus accepting overcrowded housing and low-skilled jobs associated with the onset of disease in the early years of migration (Davey-Smith et al., 2000; Graham, 2000). Against this background, it is highly likely that the Matsu emigrants did not experience the same living standard as those born on Taiwan Island. They most probably had to live with a more pressing financial situation compared to their peers born on the main island, at least initially, while also losing their original social support. It is not unlikely that this setting would bring on additional psychological distress and lead to unhealthy habits such as smoking, drinking and substance abuse (Davey-Smith et al., 2000), especially in the early years of migration (Chen, 2011). The possibility that the emigrants regularly loose initial health advantages and undergo a process of acculturation by the assimilation of the dominant culture and habits of the new location is supported by development of the standardised mortality ratio between the Matsunese immigrants and their new native neighbours in Taipei and Taoyuan, the two counties in northern Taiwan that received most of the immigrants from Matsu. It increased from 0.69 in 1997 to 1.29 in 2003 and was afterwards close to the native population using a 3-year moving average method (Armitage et al., 2002).

Although it is possible that the impact of selective emigration might bias the results (Lu, 2008), there is no support for a strong impact of selective migration on mortality in this study. For example, although the migration of younger and healthier Matsunese, rather than the elderly, would distort the results, it would have the opposite effect than that found in this study, i.e. increasing the mortality rate for the Matsu population, while lowering that of the Matsu emigrant group. Another possible effect of selective migration could be that sick people would immigrate to the main island seeking better health care there, a situation that could lead to higher mortality of emigrants as seen in a domestic migration study in Indonesia (Lu, 2008). Although detailed information on poor health was not available for this study, some indirect evidence rebuts this postulate. Besides the fact that younger people dominated in the migrants group $(73 \%$ less than 40 years old), the prevalence of diabetes mellitus was similar in the stationary Matsunese compared to the emigrants according to NHI data of 1997. In addition, the prevalence of hypertension was higher in the stationary Matsunese than in the emigrants. Although infor- mation needed to distinguish between people migrating for medical reason and those moving for other reasons is lacking, we re-analysed the mortality data after excluding people aged $\geq 60$ years in an attempt to get a better selection of healthy subjects. The result showed that emigrants still had significantly higher mortality in terms cancer of all causes, hepatocellular carcinoma and stomach cancer. Moreover, the argument of seeking better care for sick people is counteracted by the lack of significant differences in survival between the two study groups for the majority of, diseases. As survival is strongly affected by the availability of and access to, medical care, the lack of difference between the two groups does not support the selective migration hypothesis.

Previous studies have reported the paradoxical association of lower socio-economic status with lower mortality, e.g. low mortality rates for cancer, cardiovascular disease and all-cause mortality among Latin Americans relative to non-Latin Americans with better socio-economic resources (Markides and Coreil, 1986; Sorlie et al., 1993; Abraido-Lanza et al., 1999). Again, these paradoxes can be attributed to the healthy migrant effect. However, their results are not directly comparable to ours as they evaluated determinants between people of different ethnicity.

Although migrating into a place with better availability and accessibility to medical service should intuitively lead to better survival, the findings indicate this was not such a case here. There is evidence that lower levels of acculturation are associated with lower utilization rate of health services (Wells et al., 1987; Moore and Hepworth, 1994; O’Malley et al., 1999; Arcia et al., 2001) and that this association is related to language proficiency, which is the main barrier to medical services for international migrants (Arcia et al., 2001). Both Matsu emigrants and those born on Taiwan Island are covered by NHI and they speak the same language, but other reasons, e.g. social support and the time constraints (emigrants would rather use their time working than "sacrifice" it by visiting a hospital) could be a barrier for health utilization even when better medical resources are available.

The strength of our study design is three-fold. Firstly, the use of domestic migration data dispenses with ethnic group differences demonstrates more clearly the influence of non-genetic factors. Secondly, our data sources are based on comprehensive mortality and NHI data as well as the Matsu population registry and the nationwide cancer registry. We therefore did not have problems of non-response often involved in primary surveys and follow-up loss in longitudinal cohort 
studies. However, the crucial determinants associated with the mortality paradox eluded us as individual data such as lifestyle, occupation, family income, language, etc. were lacking. Aricia et al. (2001) emphasise the importance of using more complex models, including language use, language proficiency, current environment, desirable environment, ethnic identity and social acceptance that makes up the information needed to determine the exact role of acculturation, while Malmusi et al. (2010) address the role of gender, social class and deprivation in association migration-related health inequality. As family income has been shown to diminish the probability of migration in younger Indonesians ( $\mathrm{Lu}, 2008)$, we attempted to control the socio-economic status, by reanalysing the data adjusting for a proxy variable using average income in the neighbourhood where most of the emigrants resided. The results still showed a similar pattern of health inequality in terms of mortality and cancer incidence between the stationary Matsunese and those who emigrated. Admittedly, however, emigrants might not reach the average income of the neighbourhood where they live, and it is still possible that selective migration of the poorer people may bias the results. Data was not available for studying dynamic association between migration and health inequalities such as the issues about return migration and circular migration. A further study with the variable of dynamic migration is needed to address these issues. In addition to the issues mentioned above, we also lack formal comparison between Matsu emigrants and native inhabitants of Taiwan Island, which are needed to clarify the effect of selection and acculturation by using the second generation born to Matsu emigrants aged 30 years or less, who are still too young to be eligible for studying mortality and incidence of major cancer and chronic disease. Further studies focusing on the individual level, as seen in previous investigations (Graham, 2000; DesMeules et al., 2004; Malmusi et al., 2010) are needed to illuminate this counterintuitive healthy migrant hypothesis.

\section{Conclusion}

Migration from a an area characterised by lagging developed socio-economic determinants including health care to a more affluent area can have a paradoxical negative health impact. The domestic migration study between two areas within one country presented here undermines the healthy-migration postulate and attributes the higher mortality and cancer incidence encountered to the effect of negative accul- turation, psycho-social factors and risk related to the urbanized environment. Further studies based on specific information on individual factors responsible for this paradoxical phenomenon is warranted to pinpoint the exact causes.

\section{References}

Abraido-Lanza AF, Dohrenwend BP, Ng-Mak DS, Turner JB, 1999. The Latino mortality paradox: a test of the "salmon bias" and healthy migrant hypotheses. Am J Public Health 89, 1543-1548.

Adler NE, Boyce T, Chesney MA, Cohen S, Folkman S, Kahn RL, Syme SL, 1994. Socioeconomic status and health. The challenge of the gradient. Am Psychol 49, 15-24.

Afable-Munsuz A, Ponce NA, Rodriguez M, Perez-Stable EJ, 2010. Immigrant generation and physical activity among Mexican, Chinese \& Filipino adults in the U.S. Soc Sci Med 70, 1997-2005.

Andersen PK, 1992. Repeated assessment of risk factors in survival analysis. Stat Methods Med Res 1, 297-315.

Arcia E, Skinner M, Bailey D, Correa V, 2001. Models of acculturation and health behaviors among Latino immigrants to the US. Soc Sci Med 53, 41-53.

Armitage P, Berry G, Matthews JNS, 2002. Statistical methods in medical research. Oxford, Blackwell Science, 387-388 pp.

Boyle P, Norman P, Rees P, 2002. Does migration exaggerate the relationship between deprivation and limiting long-term illness? A Scottish analysis. Soc Sci Med 55, 21-31.

Brimblecombe N, Dorling D, Shaw M, 2000. Migration and geographical inequalities in health in Britain. Soc Sci Med 50, 861-878

Chen J, 2011. Internal migration and health: re-examining the healthy migrant phenomenon in China. Soc Sci Med 72, 12941301.

Chen LS, Yen MF, Wu HM, Liao CS, Liou DM, Kuo HS, Chen TH, 2005. Predictive survival model with time-dependent prognostic factors: development of computer-aided SAS Macro program. J Eval Clin Pract 11, 181-193.

Connolly S, O’Reilly D, Rosato M, 2007. Increasing inequalities in health: is it an artefact caused by the selective movement of people? Soc Sci Med 64, 2008-2015.

Davey-Smith G, Charsley K, Lambert H, Paul S, Fenton S, Ahmad W, 2000. Ethnicity, health and the meaning of socioeconomic position. In: understanding health inequalities. Graham H (ed). Oxford: Open University Press, pp. 25-37.

Department of Health, 2006a. Statistics of causes of death. Vol. 1. Taiwan Provincial Department of Health.

Department of Health, 2006b. Vital statistics in Taiwan. Vol. 1. Taiwan Provincial Department of Health.

Department of Health, 2011. 2010 Statistics of causes of death in Taiwan. Taiwan Provincial Department of Health. 
DesMeules M, Gold J, Kazanjian A, Manuel D, Payne J, Vissandée B, McDermott S, Mao Y, 2004. New approaches to immigrant health assessment. Can J Public Health 95, 22-26.

Dunn JR, Dyck I, 2000. Social determinants of health in Canada's immigrant population: results from the National Population Health Survey. Soc Sci Med 51, 1573-1593.

Franzen L, Smith C, 2009. Differences in stature, BMI, and dietary practices between US born and newly immigrated Hmong children. Soc Sci Med 69, 442-450.

General Directorate of Budget, Accounting and Statistics, 2005. Report of annual per capital gross product in 2005. Directorate-General of Budget, Accounting and Statistics, Executive Yuan, R.O.C.

Graham H, 2000. The Chanllenge of health inequalities. In: understanding health inequalities. Graham $\mathrm{H}$ (ed). Buckingham: Open University Press, 3-24.

Guilbert JJ, 2003. The world health report 2002 - reducing risks, promoting healthy life. Educ Health (Abingdon) 16, 230.

Hernández-Quevedo C, Jiménez-Rubio D, 2009. A comparison of the health status and health care utilization patterns between foreigners and the national population in Spain: new evidence from the Spanish National Health Survey. Soc Sci Med 69, 370-378.

Kelleher CC, Lynch JW, Daly L, Harper S, Fitz-Simon N, Bimpeh Y, Daly E, Ulmer H, 2006. The “Americanisation” of migrants: evidence for the contribution of ethnicity, social deprivation, lifestyle and life-course processes to the mid-20th century Coronary Heart Disease epidemic in the US. Soc Sci Med 63, 465-484.

Leyland AH, 2004. Increasing inequalities in premature mortality in Great Britain. J Epidemiol Community Health 58, 296302.

Lu Y, 2008. Test of the "healthy migrant hypothesis": a longitudinal analysis of health selectivity of internal migration in Indonesia. Soc Sci Med 67, 1331-1339.

Mackenbach JP, Kunst AE, Cavelaars AE, Groenhof F, Geurts JJ, 1997. Socioeconomic inequalities in morbidity and mortality in western Europe. The EU Working Group on Socioeconomic Inequalities in Health. Lancet 349, 1655-1659. Malmusi D, Borrell C, Benach J, 2010. Migration-related health inequalities: showing the complex interactions between gender, social class and place of origin. Soc Sci Med 71, 16101619.
Markides KS, Coreil J, 1986. The health of Hispanics in the southwestern United States: an epidemiologic paradox. Public Health Rep 101, 253-265.

Markides KS, Lee DJ, 1991. Predictors of health status in middle-aged and older Mexican Americans. J Gerontol 46, S243249.

Men T, Brennan P, Boffetta P, Zaridze D, 2003. Russian mortality trends for 1991-2001: analysis by cause and region. BMJ 327, 964.

Moore P, Hepworth JT, 1994. Use of perinatal and infant health services by Mexican-American Medicaid enrollees. JAMA 272, 297-304.

Newbold KB, 2005. Self-rated health within the Canadian immigrant population: risk and the healthy immigrant effect. Soc Sci Med 60, 1359-1370.

O’Malley AS, Kerner J, Johnson AE, Mandelblatt J, 1999. Acculturation and breast cancer screening among Hispanic women in New York City. Am J Public Health 89, 219-227.

Ontiveros J, Miller TQ, Markides KS, Espino DV, 1999. Physical and psychosocial consequences of stroke in elderly Mexican Americans. Ethn Dis. Spring-Summer 9, 212-217.

Sorlie PD, Backlund E, Johnson NJ, Rogot E, 1993. Mortality by Hispanic status in the United States. JAMA 270, 24642468.

Stephen EH, Foote K, Hendershot GE, Schoenborn CA, 1994. Health of the foreign-born population: United States, 198990. Adv Data 14, 1-12.

Uretsky MC, Mathiesen SG, 2007. The effects of years lived in the United States on the general health status of California's foreign-born populations. J Immigr Minor Health 9, 125-136. Wells KB, Hough RL, Golding JM, Burnam MA, Karno M, 1987. Which Mexican-Americans underutilize health services? Am J Psychiatry 144, 918-922.

Wen CP, Tsai SP, Chung WS, 2008. A 10-year experience with universal health insurance in Taiwan: measuring changes in health and health disparity. Ann Intern Med 148, 258-267.

Woods LM, Rachet B, Riga M, Stone N, Shah A, Coleman MP, 2005. Geographical variation in life expectancy at birth in England and Wales is largely explained by deprivation. J Epidemiol Community Health 59, 115-120.

Zunzunegui MV, Forster M, Gauvin L, Raynault MF, Douglas Willms J, 2006. Community unemployment and immigrants' health in Montreal. Soc Sci Med 63, 485-500. 


\section{Appendix}

Comparing the cumulative mortality and incidence of all-cause and specific causes in those groups with different demographic patterns is difficult (e.g. age and sex). In this study, we used Cox proportional-hazards regression model to predict the effects of all relevant factors on the survival time, i.e. time to death. The survival time of each member of a population has its own hazard function, $h_{i}(t)$ modelled as a function of three covariates (age, gender and migration) through the proportional hazards regression form:

$h_{i}(t)=h_{0}(t) \times \exp \left(\beta_{1} \times\right.$ migration $+\beta_{2} \times$ age $+\beta_{3} \times$ gender $)$,

where $\mathrm{h}_{0}(\mathrm{t})$ is an arbitrary and unspecified baseline hazard function and $\beta_{1}, \beta_{2}$ and $\beta_{3}$ the regression parameters of the corresponding variables. Then, the cumulative incidence function $\mathrm{CI}(\mathrm{t})$ and the survival function $S(t)$ can be expressed as:

$$
\begin{gathered}
\left.\mathrm{CI}(\mathrm{t})=1-\mathrm{S}(\mathrm{t})=1-\left[\mathrm{S}_{0}(\mathrm{t})\right]\right]^{\exp \left(\beta_{1} \times \text { migration }+\beta_{2} \times \text { age }+\beta_{3} \times \text { gender }\right)} \\
\left.\mathrm{S}_{0}(\mathrm{t})=\exp \left[-\int_{0}^{\mathrm{t}} \mathrm{h}_{0}(\mathrm{u}) \mathrm{du}\right)\right],
\end{gathered}
$$

where $\left.S_{0}(t)=\exp \left[-\int_{0}^{t} h_{0}(u) d u\right)\right]$ is the baseline survivor function.

We applied equation 1 to the data set of stationary Matsunese and Matsu emigrants to estimate regression coefficients and we also used Andersen's method (Andersen, 1992) to estimate the baseline hazard, both of which give predictive survival curves for both study groups controlling for age and gender. The integrated baseline hazard function can also be estimated by Andersen's method as applied by Chen et al. (2005) to predict the dynamic change of cumulative survival in hepatocellular carcinoma. The baseline hazard function $\hat{\mathrm{h}}_{0}(\mathrm{t})$ can then be estimated from the integrated hazard function. The baseline hazard function $\hat{\mathrm{h}}_{0}(\mathrm{t})$ to equation 2 was used to obtain the predictive cumulative incidence function.

\section{References}

Andersen PK, 1992. Repeated assessment of risk factors in survival analysis. Stat Methods Med Res 1, 297-315.

Chen LS, Yen MF, Wu HM, Liao CS, Liou DM, Kuo HS, Chen TH, 2005. Predictive survival model with time-dependent prognostic factors: development of computer-aided SAS Macro program. J Eval Clin Pract 11, 181-193. 